\title{
Online tools improve mental health in primary care
}

$\mathrm{M}$ ental health issues make up a big part of the workload for primary care physicians. In Ontario, about $20 \%$ of patient visits to primary care practitioners are related to mental health, and in many more visits, mental health issues underlie physical symptoms.

But most frontline health care workers often don't get much training in mental health, says Dr. Peter Selby, director of medical education at the Centre for Addiction and Mental Health $(\mathrm{CAMH})$ in Toronto. "We know that most people with mental health problems are seen in primary care. How do we make sure that doctors have access to this information that may have been missed during med school?"

On Jan. 21, CAMH, with support from the telecommunications company Bell, launched two online platforms to help support primary care practitioners dealing with patients with mental health problems.

One of the tools is a website called Portico, which Selby says is intended to provide trustworthy, curated information, as well as a meeting place for discussion and training. It provides access to common psychiatric tools as well as opportunities for training or consulting with experts. "We hope that people will see it as a trustworthy place to go for all their information needs and questions around mental health, and to get access to tools they can use in their practice."

The second is an interactive, appbased version of the popular reference book Psychiatry in Primary Care. It provides all of the book's screening tools, diagnosis guides and criteria for drug prescribing in an easily accessible and interactive format, and allows practitioners to assemble and customize their own combinations of tools and questionnaires. As they work through those questionnaires with patients, they can get immediate results and recommendations to help guide their diagnosis and treatment.

"Depression is not always easy to detect; it's very important for us to

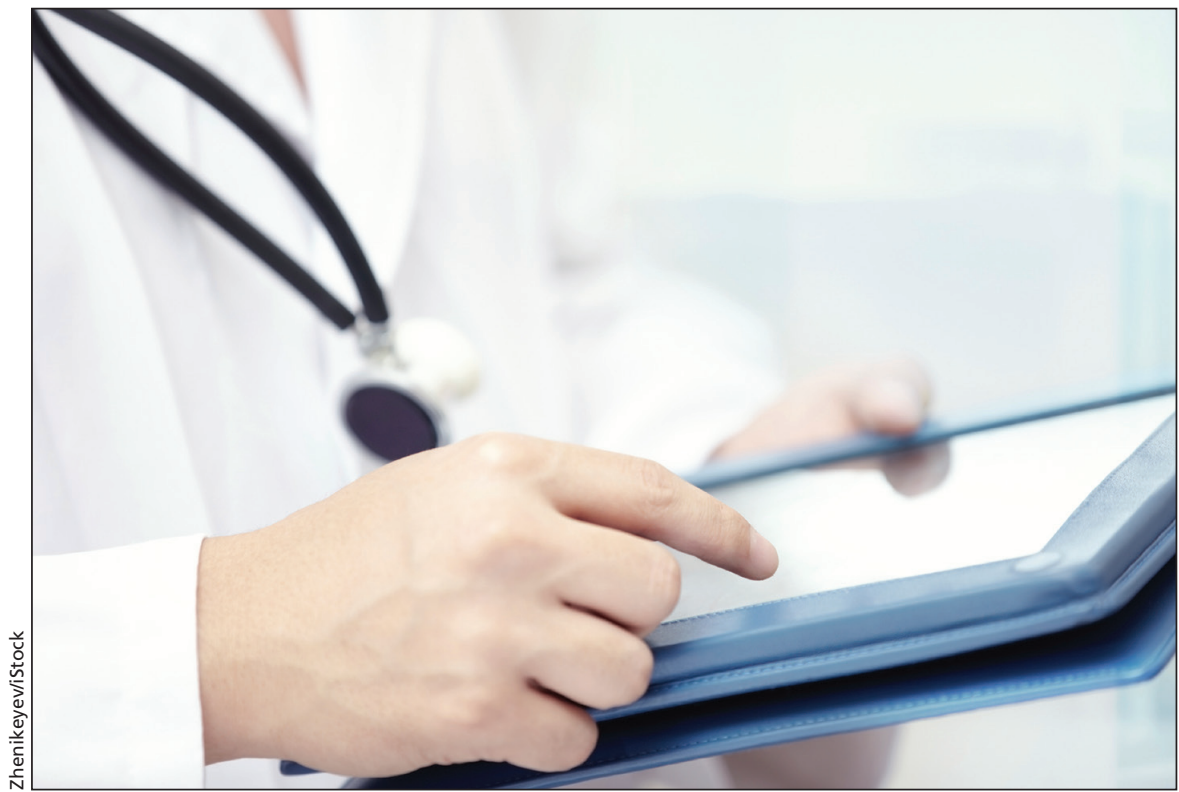

Frontline health care workers often don't get much training in mental health, yet it can account for $20 \%$ of patient visits.

probe for it," says Selby. "With the app's screening instrument, you have the questions right there at your fingertips, and you have a systematic way to follow up."

Amy Restoule, a social worker with the Sudbury East Community Health Centre servicing three small communities in the area, has been using Portico since October as part of a project to improve mental health services in rural communities. Through it, she connects with mental health experts in Toronto for advice and treatment recommendations. She recently started using the app version of Psychiatry in Primary Care, and has found that both tools have helped her become better equipped to handle complex cases.

"In primary care, professional isolation can be a challenge. It's easy to feel very alone in what we're managing," she says. "That's why I like Portico and the Psychiatry in Primary Care app; they help to reduce that isolation."

The tools also allow her to treat some clients in their own communities, rather than send them to larger centres for specialized treatment. "Not all of our clients have the means to travel to access specialized services. These tools allow me more patient time, and enable me to better serve my clients and keep them at home."

Since Portico is open not only to practitioners but also to the public, Selby hopes that it will also become a trusted source of information and support for patients and their families, and he welcomes the idea that patients may bring information they found there to doctors' offices. "Patients often bring in things that they have read in magazines or on TV shows like Dr. Oz," he says. "I'm much more likely to pay attention to something that comes from a credible source like the Portico network." He is also optimistic that it will help to open up the conversation and reduce the stigma around mental illness, both among the public and within the medical profession itself. "Having these kinds of public-facing portals really helps to ultimately reduce that stigma a little bit." - Brian Owens, St. Stephen, NB

CMAJ 2016. DOI:10.1503/cmaj.109-5227 